\section{Subdural catheterization and opiate administration in a patient with Harrington rods}

To the Editor:

We were interested to read the article "Obstetric epidural anaesthesia in patients with Harrington instrumentation" by Crosby and Halpern and agree with the authors' conclusions regarding the expected high incidence of complications in this group. ' We recently administered epidural analgesia to a patient with a history of previous Harrington instrumentation who subsequently experienced a complication which we feel was highly likely to be related to her spinal surgery.

A 31 -yr-old multiparous patient with a twin pregnancy at 36 weeks gestation was admitted for induction of labour due to the presence of mild pre-eclampsia. Harrington rods had been inserted approximately ten years earlier to the 3rd lumbar vertebra for idiopathic scoliosis; she was otherwise well. She had not received epidural analgesia for either of her previous pregnancies. She was referred to the obstetric anaesthesia service at two hours following induction. An epidural catheter was placed on the second attempt at the $\mathrm{L}_{4-5}$ level, false loss of resistance occurring initially with an inability to pass the catheter. Following a negative test-dose of lidocaine $3 \mathrm{ml}$ with epinephrine, 50 $\mu \mathrm{g}$ fentanyl were administered resulting in excellent pain relief of three hours duration, the only complication being a subjective feeling of drowsiness. After this time she complained of some discomfort and an infusion of bupivacaine 0.125 per cent at $10 \mathrm{ml} \cdot \mathrm{hr}^{-1}$ was commenced. Thirty minutes later she was still uncomfortable and a bolus of $5 \mathrm{ml}$ bupivacaine 0.125 per cent was given; $20 \mathrm{~min}$ later she had a sensory block to $\mathrm{T}_{4}$ bilaterally, the infusion was reduced to $5 \mathrm{ml} \cdot \mathrm{hr}^{-1}, 20 \mathrm{~min}$ following this her sensory level was at $\mathrm{C} 3$ and the infusion was terminated. There was no accompanying hypotension or motor block and the patient remained comfortable for the remaining three hours of labour and low forceps deliveries. Both babies emerged with Apgar scores of 8/9. The block completely resolved within two hours of delivery. No further complications ensued and the patient was completely satisfied with the analgesia provided.

The clinical course of the patient, with extensive spread of local analgesia, delayed onset and motor sparing without hypotension are consistent with subdural injection, and we feel this is the most likely explanation. The prolonged effects and drowsiness following fentanyl may also have been due to this route. As far as we are aware there have not been any other reports of subdural narcotic placement. The incidence of subdural catheterization is low $(0.05-0.82$ per cent) but it has been suggested that multiple attempts and a history of dural tap may be predisposing factors. ${ }^{2}$ It is interesting that these are also the complications likely in patients who have had previous spinal instrumentation, and in the light of this and our own experience we would recommend increased vigilance with regard to subdural catheter placement in this group.

\section{R. Howard FFARCS \\ W. Anderson MD \\ Stanford University Medical Center \\ Stanford University School of Medicine \\ Department of Anesthesia \\ Stanford, California 94305}

\section{REFERENCES}

1 Crosby ET, Halpern $S H$. Obstetric epidural anaesthesia in patients with previous Harrington instrumentation Can J Anesth 1989; 36: 693-6.

2 Stevens $R A, D^{\prime}$ arcy Stanton-Hicks $M$. Subdural injection of local anesthetic; a complication of epidural anesthesia. Anesthesiology 1985; 63: 323-6.

\section{The evolution of anaesthesia as a specialty in Canada}

To the Editor:

I very much enjoyed the interesting account presented by Dr. David Shephard in the January issue. ${ }^{1}$ While I will leave to others commentary on what Dr. Shephard refers to as Phases 1 (1847-1898) through 5 (1944-1971), I wish to point out what I consider to be a number of major omissions in his description of Phase 6 (1972-1989).

Dr. Shephard notes that the changes during Phase 6 were not as obvious as those in the earlier phases. He has chosen to emphasize only two developments. The first was the assumption by Canadian Universities of the responsibility for postgraduate training in anaesthesia. The second was a change in the size of the Canadian Anaesthetists' Society Journal and its change of title to the Canadian Journal of Anaesthesia. As I will outline below, there were a number of significant other changes and events during the period 1972-1989 which deserve recognition.

With respect to the role of the Universities in the supervision of postgraduate education, the changes which took place in anaesthesia were part of the global change affecting all internship and residency programs in Canada. While this change has had important positive implica- 
tions for all specialties, including anaesthesia, it is important to realize that the specialty of anaesthesia was the recipient (and beneficiary) of the policy change and not the instigator of the change.

For the record, I wish to remind readers that the size of the Canadian Anaesthetists' Society Journal has changed twice, first in 1983 at which time there was a total physical redesign of the Journal, and secondly in 1987, as noted by Dr. Shephard. More significant changes began in 1983 , including an expansion of the Editorial Board, with the objective of having one board member from each of the 16 Canadian University Departments of Anaesthesia. This objective was finally achieved in 1989.

I submit that the following also deserve recognition as factors of significance in the evolution of the specialty of anaesthesia in Canada since 1972.

\section{Research}

The establishment of the Canadian Anaesthetists' Society Research Award in 1985 is symbolic of the major expansion of research activities within Canadian departments of anaesthesia during the 1980's. ${ }^{2}$ By 1989 , the Research Awards Program of the Canadian Anaesthetists' Society had grown to four awards, with a commitment by the Society to the development of a fifth award.

\section{Association of Canadian University Departments of Anaesthesia (ACUDA)}

The formation of this Association in the mid-1970's should be recognized as significant in any analysis of the development of the specialty of anaesthesia in Canada. ACUDA represents the academic interests of the 16 Canadian university departments of anaesthesia. Although the role which ACUDA has played to date has varied through the years and has not met the expectations of its founders, recognition never the less is due.

\section{Anaesthetic gas machine standards}

The publication in 1978 of the world's first comprehensive anaesthetic gas machine Standard ${ }^{3}$ deserves recognition. This Preliminary Standard contained all of the basic elements of the Final Standard subsequently published in 1988, ${ }^{4}$ except for manufacturers' testing requirements. The urgent need for the Preliminary Standard resulted from the presence in Canada of a mixture of anaesthetic machines of American origin (oxygen-right) and British origin (oxygen-left), which had led to the inevitable confusion and accidents. The specialty of anaesthesia, both individual anaesthetists and their national voluntary organization, the Canadian Anaesthetists' Society, had a major role within the Canadian Standards Association in the development and publication of the anaesthetic gas machine standards.
Canadian Anaesthetists' Society Annual Meeting

During the period included within Dr. Shephard's Phase

6 , the number of scientific papers presented at the Annual Meeting of the Canadian Anaesthetists' Society has increased more than five-fold. The introduction of the popular Refresher Courses and the publication of both Scientific Abstracts and Refresher Course Outlines in the Annual Meeting Supplement of the Canadian Journal of Anaesthesia were also important developments. Successful joint meetings were held with the Australian Society of Anaesthetists (1985), and the Association of Anaesthetists of Great Britain and Ireland (1989). Attendance at the Annual Meeting more than tripled during this time period.

\section{Guidelines to the practice of anaesthesia as} recommended by the Canadian Anaesthetists' Sociery The publication of the first Guidelines in $1981^{5}$ deserves recognition. Subsequent revisions have updated the Guidelines, including reference to monitoring of oxygenation (pulse oximetry), and of ventilation in intubated patients in the operating room (capnography). ${ }^{6}$ The publication of the Guidelines was not without resistance and criticism. Subsequent events world-wide have shown that Canada was in a leadership position with its early publication of the Guidelines.

\section{Canadian Anaesthetists' Society}

Although it may be self-evident to the reader from the above summaries, I feel it is important to emphasize the very positive role played by the Society during the period 1972-1989 in the support of research, communication of research through the Annual Meeting and the Canadian Journal of Anaesthesia and the development and publication of Standards of Practice and Anaesthetic Equipment Standards. The CAS has also forged new links with ACUDA and with the Specialty Committee on Anaesthesia of the Royal College of Physicians and Surgeons of Canada, through participation by representatives of those bodies on the Governing Council of the Society.

I submit the above as one individual's view of some important hallmarks of the evolution of the specialty of anaesthesia in Canada during the period 1972-89. I suspect that others may have a different view of our recent history, and I look forward to their interpretations.

Douglas B. Craig MD FRCPC

Department of Anaesthesia

Health Sciences Centre,

University of Manitoba

Winnipeg, Manitoba 


\section{REFERENCES}

I Shephard DAE. The evolution of anaesthesia as a specialty in Canada. Can J Anaesth 1990; 37: 134-42.

2 Bevan DR, Craig DB. Editorial. The Canadian Anaesthetists' Society Research Award. Can Anaesth Soc J 1985; 32: 460-2.

3 Continuous flow inhalation anaesthetic apparatus (anaesthetic machines) for medical use. C.S.A. Preliminary Standard Z168.3-M1978. Canadian Standards Association, Rexdale, Ontario (1978).

4 Continuous flow inhalation anaesthetic apparatus (anaesthetic machines) for medical use. C.S.A. Standard Z168.3-M1980. Canadian Standards Association, Rexdale, Ontario (1980).

5 Guidelines for the basic standards of practise of anaesthesia. Canadian Anaesthetists' Society, Toronto, Ontario (1981).

6 Guidelines to the practise of Anaesthesia as recommended by the Canadian Anaesthetists' Society. Canadian Anaesthetists' Society, Toronto, Ontario (1987).

\section{REPLY}

$I$ appreciate the comments of Dr. Craig concerning the evolution of anaesthesia as a specialty in Canada. Any differ. ence of viewpoint that he and I may have may be attributed to a difference in perspective. In just a short essay I was attempting to summarize some of the main features in the evolution of a specialty over some decades, and I had to be strictly selective in what I chose to emphasize.

Because l elected to stress the broader aspects of the evolution of a specialty rather than that of a specialty society, I omitted such important events as the annual meetings of the Canadian Anaesthetists' Society and the Society's Research Award. Because I wished to emphasize the historical development of the specialty, as opposed to the daily practice of anaesthesia in Canada, I did not refer to the Association of Canadian University Departments of Anaesthesia, or to standards relating to the practice of anaesthesia and to anaesthesia machines. As Dr. Craig correctly states, all of these developments have enhanced the standard of Canadian anaesthesia over the years and have led to a maturation of anaesthesia in Canada.

Dr. Craig's comments are welcome, for they heighten our awareness of how anaesthesia, in all its aspects, has evolved in Canada, and how recognition of what is essential to good anaesthesia has, over the past nine decades, become part of our daily practice in the specialty of anaesthesia in this country.

David A.B. Shephard MB FRCPC

Saskatoon

\section{Erratum}

Zorrow MH, Thomas TC, Scheller MS. "The efficacy of three different methods of transtracheal ventilation." Can J Anaesth 1989; 36: 624-8.

The second line of the caption for Figure 2 on Page 626 should read:

baseline I, B2 = baseline 2) Significance $-\S=$ Jet $<$ Flush $<$

not

baseline 1, B2 $=$ baseline 2) Significance $-\S=$ Jet $>$ Flush $>$ 